\title{
Clinical and laboratory approaches in the diagnosis of renal tubular acidosis
}

\author{
Fernando Santos ${ }^{1,2} \cdot$ Flor A. Ordóñez ${ }^{1}$. \\ Débora Claramunt-Taberner ${ }^{1} \cdot$ Helena Gil-Peña ${ }^{1}$
}

Received: 26 September 2014 / Revised: 16 January 2015 / Accepted: 2 March 2015 / Published online: 1 April 2015

(C) IPNA 2015

\begin{abstract}
In the absence of a gastrointestinal origin, a maintained hyperchloremic metabolic acidosis must raise the diagnostic suspicion of renal tubular acidosis (RTA). Unlike adults, in whom RTA is usually secondary to acquired causes, children most often have primary forms of RTA resulting from an inherited genetic defect in the tubular proteins involved in the renal regulation of acid-base homeostasis. According to their pathophysiological basis, four types of RTA are distinguished. Distal type 1 RTA, proximal type 2 RTA, mixed-type 3 RTA, and type 4 RTA can be differentiated based on the family history, the presenting manifestations, the biochemical profile, and the radiological findings. Functional tests to explore the proximal wasting of bicarbonate and the urinary acidification capacity are also useful diagnostic tools. Although currently the molecular basis of the disease can frequently be discovered by gene analysis, patients with RTA must undergo a detailed clinical study and laboratory work-up in order to understand the pathophysiology of the disease and to warrant a correct and accurate diagnosis.
\end{abstract}

Keywords Renal tubular acidosis · Metabolic acidosis . Inherited diseases $\cdot$ Diagnosis $\cdot$ Functional tests

\section{Introduction}

The term renal tubular acidosis (RTA) refers to a group of chronic diseases characterized by hyperchloremic metabolic acidosis

Partly financed by: Fondos FEDER, Instituto de Salud Carlos III and Fundación Nutrición y Crecimiento.

Fernando Santos

fsantos@uniovi.es

1 Division of Pediatric Nephrology, Department of Pediatrics, Hospital Universitario Central de Asturias, University of Oviedo,

Oviedo, Asturias, Spain

2 Facultad de Medicina, Área de Pediatría, c/ Julián Clavería 6, 33006 Oviedo, Spain caused by the inability of the renal tubule to retain bicarbonate $\left(\mathrm{HCO}_{3}{ }^{-}\right)$or to secrete hydrogen ions $\left(\mathrm{H}^{+}\right)$in the presence of normal or mildly impaired glomerular filtration rate. Although in adults RTA is frequently diagnosed in the context of systemic diseases or exposure to drugs or toxins, most pediatric cases correspond to primary disorders resulting from specific genetic defects in a protein involved in the processes of $\mathrm{HCO}_{3}{ }^{-}$reabsorption, $\mathrm{HCO}_{3}{ }^{-}$regeneration and $\mathrm{H}^{+}$secretion [1].

This review will focus on the clinical and biochemical findings that will lead to the diagnosis of RTA, with special emphasis on the basis and the practical aspects of functional tests useful for an accurate diagnosis. The underlying molecular defect should also be identified for a complete characterization of primary RTA [2]. However, it is of note that conventional sequencing of genes so far known to cause primary distal RTA (see below) does not disclose mutations in up to $20-25 \%$ of patients. It is also worth noting that nowadays a growing number of children with clinical suspicion of RTA are probably insufficiently studied from a pathophysiological point of view as a result of the broader availability of genetic analysis.

According to their pathophysiological basis, the following types of RTA are distinguished: type 1 RTA is caused by the inability of the distal convoluted tubule and the collecting tubule to maximally increase the urinary elimination of $\mathrm{H}^{+}$in the presence of metabolic acidosis; type 2 RTA results from impaired $\mathrm{HCO}_{3}{ }^{-}$reabsorption in the proximal tubule; type $3 \mathrm{RTA}$ is a mixed form of type 1 and type 2 RTA; type 4 RTA is caused mainly by defective production of ammonium $\left(\mathrm{NH}_{4}{ }^{+}\right)$resulting from either aldosterone deficiency or aldosterone resistance [3].

\section{Clinical approach to diagnosis}

Table 1 summarizes the genetic and molecular basis, as well as the clinical, biochemical, and radiological findings useful to identify the subtype of RTA [1-12]. Information on acquired forms of RTA secondary to drugs and toxins or associated to systemic diseases is not included because this review mostly 


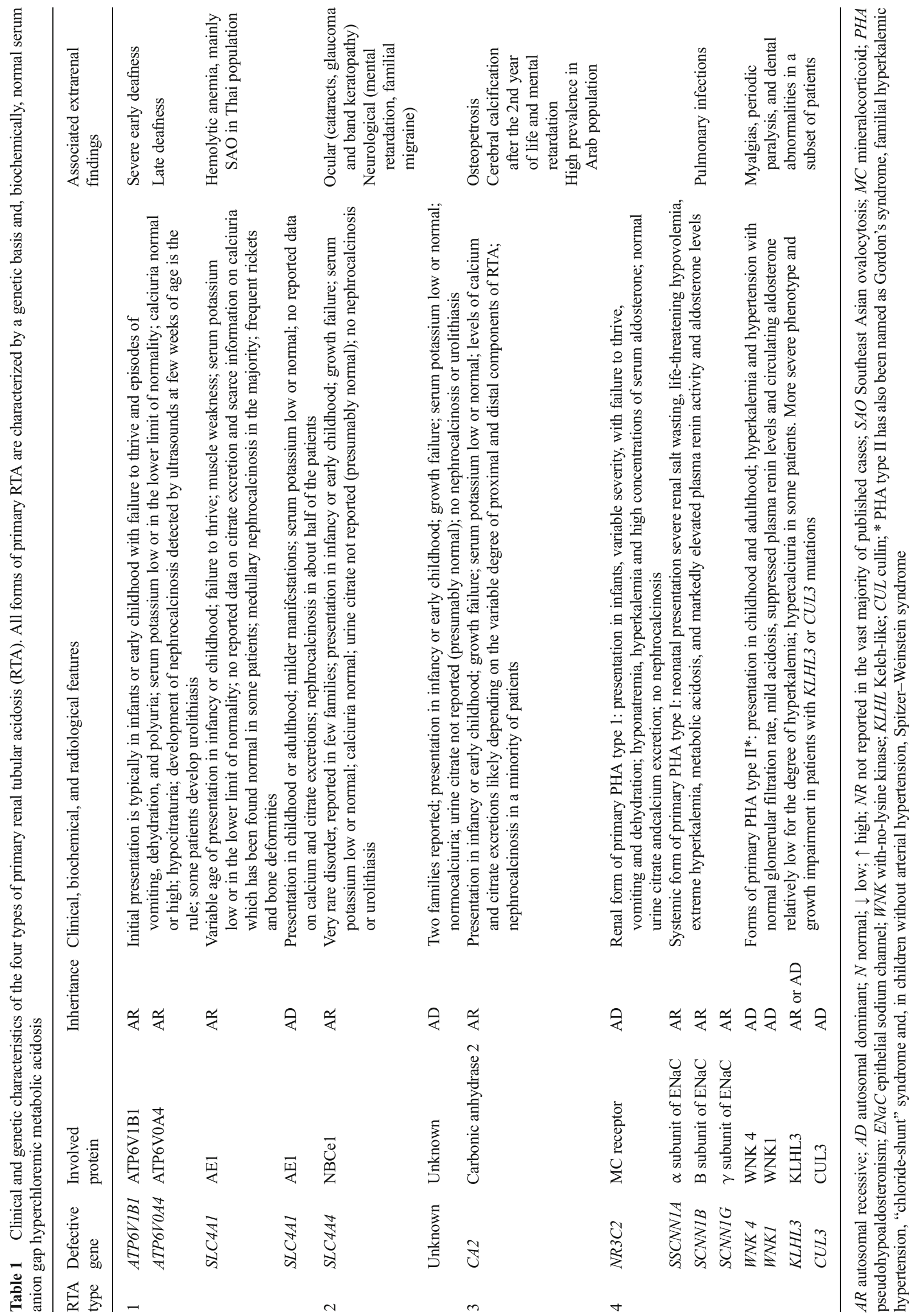


deals with congenital primary types of RTA, which are more frequently found in pediatric patients.

Most types of primary RTA present early, within the first weeks or months of life. The study of the family history may facilitate diagnosis because of the disease's hereditary transmission and the higher occurrence of some forms of RTA in particular population groups. It should be pointed out that in the forms of RTA that follow an autosomal recessive pattern of transmission, the parents are carriers and the patient being evaluated may be the first in the family to have the disease.

Type 1 distal RTA is the most common form of primary RTA in Western countries. It is characterized by the inability to maximally decrease urine $\mathrm{pH}$ and enhance urinary $\mathrm{NH}_{4}{ }^{+}$ excretion in the presence of sustained metabolic acidosis, hypokalemia, early development of nephrocalcinosis, and frequent association with nerve deafness.

Isolated type 2 proximal RTA, caused by a decrease in the renal threshold for $\mathrm{HCO}_{3}{ }^{-}$reabsorption in the absence of alterations in the transport of other solutes, is extremely rare. The vast majority of genetic forms of type 2 proximal RTA are found as a component of Fanconi syndrome caused by inborn metabolic diseases (e.g., cystinosis) rather than isolated proximal RTA. The distinctive feature of proximal RTA is the massive waste of $\mathrm{HCO}_{3}{ }^{-}$that makes it difficult to achieve and maintain normal bicarbonatemia values in spite of high doses of alkali. When the serum $\mathrm{HCO}_{3}{ }^{-}$concentration falls below the renal threshold, bicarbonaturia ceases and the urine $\mathrm{pH}$ becomes acidic.

Type 3 RTA has proximal (type 2 RTA) and distal (type 1 RTA) components. In addition to type 3 RTA caused by loss of function of carbonic anhydrase (CA) 2, as mentioned in Table 1 , cases of permanent distal type 1 RTA with transiently impaired proximal reabsorption of $\mathrm{HCO}_{3}{ }^{-}$can be found in infants; this form of type 3 RTA should not be considered as a separate entity from distal type 1 RTA.

Type 4 hyperkalemic RTA of hereditary origin is most frequently observed in children with resistance to the action of aldosterone, mainly primary pseudohypoaldosteronism (PHA) type 1. As shown in Table 1, recent findings have shed light on the molecular basis of type 2 PHA, a rare entity.

Type 4 RTA diagnosed in patients with renal chronic interstitial nephropathies (aldosterone resistance) associated with some degree of renal failure, as well as a form of hyperkalemic distal type 1 RTA described in pediatric patients with hydronephrosis, have not been included in Table 1 because they are not considered as inherited or primary.

\section{Laboratory approach to diagnosis}

\section{Basal studies}

Plasma anion gap (AG) Plasma or serum AG must be the first biochemical work-up in the diagnosis of a child with chronic metabolic acidosis. All types of RTA are characterized by hyperchloremic metabolic acidosis, i.e., normal AG. For the reliable interpretation of plasma $A G$, calculated as $\left(\mathrm{Na}^{+}+\mathrm{K}^{+}\right)-\left(\mathrm{Cl}^{-}+\mathrm{HCO}_{3}{ }^{-}\right)$, the range of normal values of $\mathrm{AG}$ should be determined for each laboratory and even for each individual compared with the baseline values, although this is difficult to accomplish in the clinical setting. The AG value represents the difference between unmeasured anions and unmeasured cations, and is affected by variations in the plasma concentrations of albumin, phosphate, calcium, and magnesium [13].

Urinary ammonium and $\mathbf{p H}$ In the study of metabolic acidosis, $\mathrm{NH}_{4}^{+}$and $\mathrm{pH}$ should be measured in conjunction in the same urine sample and when the patient is acidotic. A normal response of kidneys to metabolic acidosis involves the lowering of urine $\mathrm{pH}$ and the stimulus of production and urinary elimination of $\mathrm{NH}_{4}^{+}$. A normal adult under a common Western diet eliminates about $40 \mathrm{mEq} /$ day of $\mathrm{NH}_{4}^{+}$. This figure is greater in children when estimated on a perkilogram basis because of the production of $\mathrm{H}^{+}$that results from the formation of new bone. It is worth noting that chronic metabolic acidosis gives rise to a marked increase of urinary $\mathrm{NH}_{4}^{+}$, even up to 5-8 times the normal value, which may preclude the maximum decrease of urine $\mathrm{pH}$ that reflects free $\mathrm{H}^{+}$concentrations, whereas short-term metabolic acidosis results in a minimum urine $\mathrm{pH}<5.5$, but urinary $\mathrm{NH}_{4}{ }^{+}$concentrations do not increase maximally. For an accurate interpretation of urine $\mathrm{pH}$ and $\mathrm{NH}_{4}{ }^{+}$values, it should also be kept in mind that highly diluted urine, a very low concentration of urinary sodium, and bacterial growth may all interfere with the normal achievement of a minimum $\mathrm{pH}$ without intrinsic defects of renal acidification $[14,15]$.

Urinary AG The majority of clinical laboratories do not measure $\mathrm{NH}_{4}{ }^{+}$in urine because it is cumbersome. The urinary AG $\left(\mathrm{Na}^{+}+\mathrm{K}^{+}-\mathrm{Cl}^{-}\right)$may be considered an indirect index of urinary $\mathrm{NH}_{4}{ }^{+}$excretion in the presence of hyperchloremic metabolic acidosis [16]. High concentrations of $\mathrm{NH}_{4}{ }^{+}$are associated with high concentrations of $\mathrm{Cl}^{-}$and the urine $\mathrm{AG}$ becomes negative. Positive values $\left(\mathrm{Na}^{+}+\mathrm{K}^{+}>\mathrm{Cl}^{-}\right)$indicate inappropriately low $\mathrm{NH}_{4}{ }^{+}$excretion. However, some limitations must be kept in mind, for example, the correlation between urinary AG and $\mathrm{NH}_{4}{ }^{+}$has been shown to be weak in neonates and young infants [17].

Urinary osmolal gap Likewise, urinary AG does not correlate with $\mathrm{NH}_{4}{ }^{+}$when this is excreted in the company of anions other than $\mathrm{Cl}^{-}$. In this case, urinary $\mathrm{NH}_{4}{ }^{+}$can be roughly estimated by calculating the urine osmolal gap, i.e., urine osmolality $-\left(2 \mathrm{Na}^{+}+2 \mathrm{~K}^{+}+\right.$urea + glucose $)$with urea and 
glucose concentrations expressed in $\mathrm{mmol} / \mathrm{l}$ (to convert from $\mathrm{mg} / \mathrm{dl}$ to $\mathrm{mmol} / \mathrm{l}$, divide by 2.8 and 18 , respectively). A value $>100 \mathrm{mOsm} / \mathrm{kg} \mathrm{H} \mathrm{H}_{2} \mathrm{O}$ suggests high urinary $\mathrm{NH}_{4}{ }^{+}[18,19]$. This method is valuable for bedside screening for gross changes in urinary $\mathrm{NH}_{4}^{+}$concentration and is used in the diagnostic study of patients with diabetic ketoacidosis or D-lactic acidosis [13].

\section{Functional tests}

Ammonium chloride load The medical literature describes the use of several acidifying agents, such as ammonium chloride $\left(\mathrm{NH}_{4} \mathrm{Cl}\right)$, calcium chloride and arginine hydrochloride, to explore the renal response to metabolic acidosis that consists of stimulation of distal excretion of $\mathrm{H}^{+}$, increased proximal ammoniagenesis and trapping of $\mathrm{NH}_{4}{ }^{+}$in the collecting duct lumen.

Administration of $\mathrm{NH}_{4} \mathrm{Cl}$ has been the most often utilized and it has classically been considered a crucial test in the diagnosis of distal RTA [20]. However, nowadays its clinical application is quite restricted because patients with RTA are spontaneously acidotic. The $\mathrm{NH}_{4} \mathrm{Cl}$ test is poorly tolerated since it induces nausea and vomiting, and the ability to acidify the urine may be assessed with less aggressive explorations (see below). A single dose of $75 \mathrm{mEq} / \mathrm{m}^{2}$ of $\mathrm{NH}_{4} \mathrm{Cl}$ in infants administered diluted via nasogastric tube or $150 \mathrm{mEq} / \mathrm{m}^{2}$ in children over $1 \mathrm{~h}$ in gelatin-coated capsules has usually been given, collecting subsequent urine samples over approximately a 6-8-h period. Relatively lower doses of $100 \mathrm{mg} / \mathrm{kg}(53.5 \mathrm{mg}=$ $1 \mathrm{mEq}$ ) have been used in adults [21]. The test must be validated by confirming that the $\mathrm{NH}_{4} \mathrm{Cl}$ dose induces metabolic acidosis: $\mathrm{tCO}_{2}$ in blood at least $<18 \mathrm{mmol} / \mathrm{l}$ in infants and $<21 \mathrm{mmol} / 1$ in older children. In normal individuals urine $\mathrm{pH}$ drops below 5.5 and urinary $\mathrm{NH}_{4}{ }^{+}$increases up to $57 \pm 14($ mean $\pm \mathrm{SD}) \mu \mathrm{Eq} / \mathrm{min} / 1.73 \mathrm{~m}^{2}$ in infants aged $1-16$ months and $80 \pm 12 \mu \mathrm{Eq} / \mathrm{min} / 1.73 \mathrm{~m}^{2}$ in children aged 7-12 years [22]. The capacity of urinary acidification is blunted in patients with distal RTA and preserved in patients with proximal RTA, when the plasma $\mathrm{HCO}_{3}{ }^{-}$is below the renal threshold, and patients with type 4 RTA. As for $\mathrm{NH}_{4}{ }^{+}$excretion, it is low in children with type 1 and type 3 RTA (defective secretion of $\mathrm{H}^{+}$) as well as in type 4 RTA (resistance to aldosterone) and it is expected to be normal in children with pure type 2 RTA.

Administration of $\mathrm{NH}_{4} \mathrm{Cl}$ for a 3-day period represents a more potent stimulus for $\mathrm{NH}_{4}{ }^{+}$excretion. Adults with isolated proximal RTA retain their ability to acidify urine normally in response to 3 -day $\mathrm{NH}_{4} \mathrm{Cl}$ loading $(2 \mathrm{mEq} / \mathrm{kg}$ / day by oral route), but their elimination of urinary $\mathrm{NH}_{4}^{+}$ is inappropriately low in comparison with healthy controls, likely reflecting the impairment of proximal ammoniagenesis [23].
Bicarbonate load This test allows the calculation of the fractional excretion (FE) of $\mathrm{HCO}_{3}{ }^{-}$when the plasma $\mathrm{HCO}_{3}{ }^{-}$concentration is normal and the urine-to-blood (U-B) $\mathrm{pCO}_{2}$ difference when the urine becomes more alkaline than the blood. $\mathrm{FE}$ of $\mathrm{HCO}_{3}{ }^{-}$is determined by collecting the urine sample under mineral oil and using the formula (Urine $\mathrm{HCO}_{3}{ }^{-} \times$ Plasma creatinine $\times 100) /\left(\right.$ Plasma $\mathrm{HCO}_{3}{ }^{-} \times$Urine creatinine). It should be remembered that introduction of oil into the gas analyzer may damage the equipment, so special care must be taken in the analysis of these oil-protected urine samples.

In proximal RTA, large amounts of $\mathrm{HCO}_{3}{ }^{-}$are excreted when plasma $\mathrm{HCO}_{3}{ }^{-}$is above the renal threshold, whereas in patients with distal RTA, the bicarbonaturia is normal unless there is a transient proximal $\mathrm{HCO}_{3}{ }^{-}$ wasting, as found in some infants in whom the FE of $\mathrm{HCO}_{3}{ }^{-}$has been reported to range from 6 to $15 \%$ in the presence of normal plasma $\mathrm{HCO}_{3}{ }^{-}$achieved during intravenous infusion of sodium $\mathrm{HCO}_{3}{ }^{-}[24,25]$. In patients diagnosed with CA 2 deficiency and primary type 3 RTA, the values of $\mathrm{FE}$ of $\mathrm{HCO}_{3}{ }^{-}$with normal bicarbonatemia depend on the severity of the impairment of proximal $\mathrm{HCO}_{3}{ }^{-}$reabsorption, but the amounts of oral alkali needed to correct the acidosis are much lower than in patients with pure type 2 proximal RTA [26], indicating that the loss of urinary $\mathrm{HCO}_{3}{ }^{-}$is not that high [26-28]. In type $4 \mathrm{RTA}, \mathrm{FE}$ of $\mathrm{HCO}_{3}{ }^{-}$in the setting of normal plasma $\mathrm{HCO}_{3}{ }^{-}$is usually considered to be between 5 and $10 \%$, although very little data based on clinical studies are available [29].

This test is usually performed by administering $4 \mathrm{mEq} / \mathrm{kg}$ of oral sodium bicarbonate $(1 \mathrm{~g}=12 \mathrm{mEq})$ [30]. However, this dose does not normalize plasma $\mathrm{HCO}_{3}{ }^{-}$in a large proportion of patients with marked $\mathrm{HCO}_{3}{ }^{-}$wasting, such as those with proximal RTA. These patients require larger doses of oral bicarbonate [10] or the intravenous infusion of a $3.75 \%$ solution of sodium $\mathrm{HCO}_{3}{ }^{-}$at rates varying from 0.3 to $0.8 \mathrm{ml} / \mathrm{min}$ to cause an increment of $2-3 \mathrm{mEq} / \mathrm{l} / \mathrm{h}$ of plasma $\mathrm{HCO}_{3}{ }^{-}$and to minimize extracellular volume expansion, as classically reported [24]. However, even if a normal plasma $\mathrm{HCO}_{3}{ }^{-}$concentration is not achieved, the verification of massive bicarbonaturia when plasma $\mathrm{HCO}_{3}{ }^{-}$is below normal levels is likely better evidence of defective proximal reabsorption [3, 31].

The measurement of urine $\mathrm{pCO}_{2}$ when the urinary $\mathrm{pH}$ is higher than that of blood is a sensitive index of distal nephron $\mathrm{H}^{+}$secretion. A favorable chemical gradient facilitates $\mathrm{H}+$ secretion by the collecting duct. Within the tubular lumen, $\mathrm{H}^{+}$ions combine with $\mathrm{HCO}_{3}{ }^{-}$to form $\mathrm{H}_{2} \mathrm{CO}_{3}$, which as a result of the lack of $\mathrm{CA}$ in the luminal side of this segment of the nephron, dehydrates slowly into $\mathrm{CO}_{2}$ and water. The unfavorable surface-to-volume relationship limits $\mathrm{CO}_{2}$ diffusion out of the lumen and generates a high $\mathrm{pCO}_{2}$ in the renal 
medulla and final urine. Provided that urine $\mathrm{pH}$ and $\mathrm{HCO}_{3}{ }^{-}$ concentration increase above 7.6 and $80 \mathrm{mEq} / 1$, respectively, the U-B $\mathrm{pCO}_{2}$ gradient should be greater than $20 \mathrm{mmHg}$ in normal individuals. In patients with primary type 1 distal RTA the U-B $\mathrm{pCO}_{2}$ value is around 0 or may even be negative, whereas it is expected to be normal in type 2 RTA and type 4 RTA. In patients with osteopetrosis and CA deficiency (type 3 RTA), acidification is impaired and U-B $\mathrm{pCO}_{2}$ in alkaline urine has been reported to be low [28]. However, two children reported by Ohlsson et al. [26] had normal values of 64 and $40 \mathrm{mmHg}$ of U-B $\mathrm{pCO}_{2}$ in the setting of alkaline urine induced by sodium bicarbonate treatment $(5-6 \mathrm{mEq} / \mathrm{kg} / \mathrm{day})$.

Acetazolamide administration Acetazolamide inhibits CA 2, thus decreasing $\mathrm{HCO}_{3}{ }^{-}$reabsorption at the proximal tubule and causing enhanced bicarbonaturia. Alon et al. [32] reported that the difference in U-B $\mathrm{pCO}_{2}$ in alkaline urine induced by oral acetazolamide was comparable to that obtained after a dose of $2.5 \mathrm{mEq} / \mathrm{kg}$ of sodium bicarbonate in children and adolescents with normal and disturbed distal acidification capacity. The maximum urinary $\mathrm{pH}$ after administration of the alkalinizing agent was achieved more rapidly with acetazolamide than with sodium bicarbonate (160 vs. $116 \mathrm{~min}$ ) and acetazolamide was more palatable and better tolerated. On the basis of these results, the authors concluded that oral acetazolamide, at a dose of $15-20 \mathrm{mg} / \mathrm{kg}$, can replace sodium bicarbonate in the assessment of U-B $\mathrm{pCO}_{2}$. Interestingly, assessment of urine $\mathrm{pH}$ and $\mathrm{HCO}_{3}{ }^{-}$ excretion following intravenous acetazolamide has been found to be no different in patients with CA deficiency and healthy controls [33].

Furosemide test Furosemide blocks the $\mathrm{Na}^{+}-\mathrm{K}^{+}-2 \mathrm{Cl}^{-}$ cotransporter in the thick ascending limb of the loop of Henle, thus increasing the delivery of sodium chloride to the distal segments of the nephron. This stimulates sodium ion reabsorption by the cortical collecting duct and generates a favorable lumen-negative transtubular voltage that, in turn, stimulates secretion of $\mathrm{H}^{+}$and potassium to urine. Thus, administration of furosemide to normal individuals results in acidification of urine in association with a kaliuretic response and an increase of $\mathrm{NH}_{4}$ excretion [34]. Furosemide causes a sharp decrease of urinary $\mathrm{pH}$ by a mechanism completely different to $\mathrm{NH}_{4} \mathrm{Cl}$ and without inducing metabolic acidosis. Furosemide is usually given at a dose of $1 \mathrm{mg} / \mathrm{kg}$ either by intravenous or oral route and urine samples are collected for a period of $4 \mathrm{~h}$. Urine $\mathrm{pH}$ drops below 5.3 whereas urine $\mathrm{NH}_{4}{ }^{+}$and potassium excretion increase $2-3$ times, approximately, with respect to baseline values [34, 35]. Intravenous administration of furosemide causes marked increases in plasma renin activity and aldosterone concentration, whereas the activities these hormones do not increase significantly when the diuretic is given by mouth. This difference may be important when evaluating patients with hyperkalemic RTA. Patients with reduced distal $\mathrm{H}^{+}$secretion as a result of either low distal delivery of sodium (e.g., nephrotic syndrome), or impaired, but reversible, sodium distal reabsorption (e.g., sickle cell anemia or lithium administration), will respond normally to the furosemide test, whereas patients with primary distal type 1 RTA do not correct the acidification defect or the low $\mathrm{NH}_{4}^{+}$excretion.

Furosemide+fludrocortisone test The simultaneous administration of furosemide and fludrocortisone has been proposed to replace administration of $\mathrm{NH}_{4} \mathrm{Cl}$ in the diagnosis of distal RTA [21]. The advantage of adding fludrocortisone to furosemide is that the mineralocorticoid action stimulates reabsorption of sodium by the principal cells of the collecting duct a few minutes after its administration, thus facilitating the secretion of $\mathrm{H}^{+}$and the decrease of urinary $\mathrm{pH}$. The test is better tolerated that the $\mathrm{NH}_{4} \mathrm{Cl}$ load and causes a decrease of urinary $\mathrm{pH}$ and an increase of urinary $\mathrm{NH}_{4}{ }^{+}$in a shorter period of time. Oral administration of $40 \mathrm{mg}$ of furosemide and $1 \mathrm{mg}$ of fludrocortisone to healthy adults acidifies the urine to a $\mathrm{pH}<5.3$ and increases $\mathrm{NH}_{4}+$ excretion up to $85 \pm 23 \mu \mathrm{Eq} / \mathrm{min}$ (mean $\pm \mathrm{SE}$ ), whereas patients with distal RTA fail to acidify their urine to $\mathrm{pH}<5.3$ and do not significantly increase $\mathrm{NH}_{4}^{+}$excretion over the basal values.

Table 2 proposes summarized practical protocols for the clinical application of the above-described functional tests in the diagnosis of primary RTA in infants and children. Other tests, such as phosphate or sulfate loads, are not indicated in the study of pediatric patients with primary types of RTA, but can be of some usefulness to explore the origin of renal acidification defects (back flux of secreted $\mathrm{H}^{+}$, voltage-, gradient-defects) mainly in adults with secondary forms of RTA.

\section{Summary of integrated diagnostic approach}

Metabolic acidosis in children is usually found in the setting of acute diseases, such as systemic infections, dehydration, etc. In the presence of maintained or frequently recurrent metabolic acidosis, the following diagnostic work-up is proposed:

- High plasma $\mathrm{AG} \rightarrow$ look for inherited metabolic diseases, ingestion of toxins, or advanced chronic renal failure.

- Normal plasma $A G \rightarrow$ diarrhea causing fecal loss of $\mathrm{HCO}_{3}{ }^{-}$as the first diagnostic option; in acidosis, patients have normal ability to decrease urine $\mathrm{pH}$ and negative urinary AG.

- Normal plasma $\mathrm{AG}+$ absence of gastrointestinal disorder+normal ability to maximally acidify urine + negative 


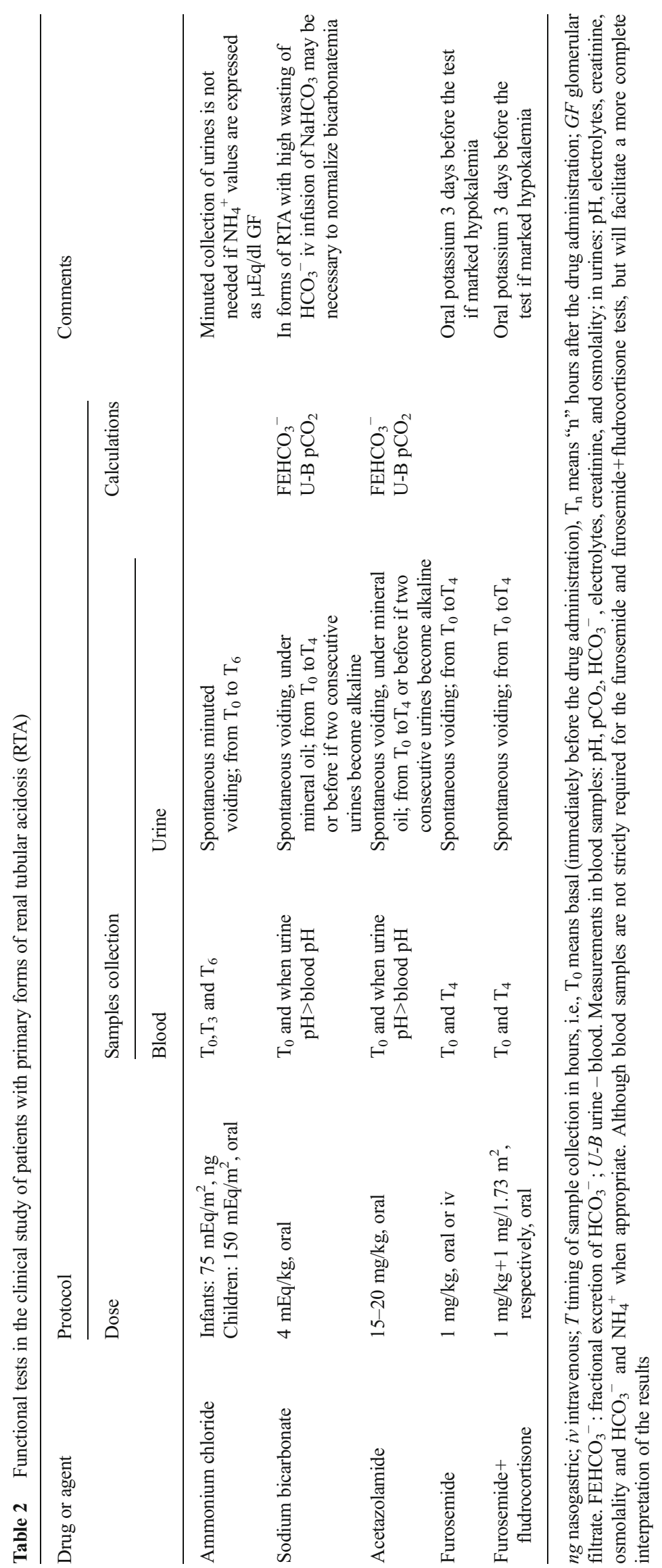


Table 3 Differential diagnosis of primary types of renal tubular acidosis (RTA) based on laboratory work-up findings in conditions of spontaneous metabolic acidosis or in response to functional tests if applicable, as explained in the manuscript's text

\begin{tabular}{|c|c|c|c|c|}
\hline & Type 1 distal RTA & Type 2 proximal RTA & Type 3 RTA & Type 4 RTA \\
\hline \multicolumn{5}{|l|}{ In the presence of acidosis } \\
\hline - Plasma anion gap & Normal & Normal & Normal & Normal \\
\hline - Urinary $\mathrm{NH}_{4}^{+} *$ & Low & Normal & Low & Low \\
\hline - Plasma potassium & Low/normal ${ }^{* *}$ & Low/normal & Low/normal & High \\
\hline - Minimal urinary $\mathrm{pH}$ & $>5.5$ & $<5.5$ & $>5.5$ & $<5.5$ \\
\hline \multicolumn{5}{|l|}{ With normal bicarbonatemia } \\
\hline - Fractional excretion of bicarbonate & $<5 \%$ & $>10-15 \%$ & $>5 \%$ & $>5-10 \%$ \\
\hline - Urine - blood $\mathrm{pCO}_{2}(\mathrm{~mm} \mathrm{Hg})$ in alkaline urine & $<20$ & $>20$ & $<20$ & $>20$ \\
\hline
\end{tabular}

*Directly measured and/or indirectly estimated by urinary anion gap. The urinary osmolal gap can be used as a rough indirect index of ammonium excretion in selected cases (see text)

**There are forms of hyperkalemic distal RTA in children with obstructive uropathy

urinary $\mathrm{AG}$ or high $\mathrm{NH}_{4}{ }^{+}$elimination in the presence of acidosis $\rightarrow$ think of proximal RTA; to confirm it, urine $\mathrm{pH}$ below 5.5 when the child is acidotic and massive bicarbonaturia following bicarbonate load should be demonstrated. Primary pure RTA is exceptional. Investigate signs of proximal tubular dysfunction (low molecular weight proteinuria, hyperaminoaciduria, glucosuria, hypophosphatemia with relative hyperphosphaturia, hypouricemia with relative hyperuricosuria) since the majority of proximal RTAs form part of Fanconi syndrome, idiopathic or secondary to toxics or metabolic diseases (e.g., cystinosis).

- Normal plasma $\mathrm{AG}+$ low $\mathrm{NH}_{4}{ }^{+}$excretion in urine, assessed by indirect indexes or, preferably, by direct determination $\rightarrow$ look at plasma potassium concentration.

- Normal plasma $\mathrm{AG}+$ low $\mathrm{NH}_{4}{ }^{+}$excretion in urine+ hyperkalemia+normal capacity to lower urine $\mathrm{pH} \rightarrow$ type 4 RTA $\rightarrow$ look for obstructive uropathy and renal failure.

- Type $4 \mathrm{RTA}+$ normal glomerular filtration rate+absence of structural abnormalities of the kidneys and urinary tract $\rightarrow$ study sodium and potassium metabolism, including plasma renin activity and aldosterone, to confirm hypoaldosteronism or pseudohypoaldosteronism.

- Normal plasma $\mathrm{AG}+$ low $\mathrm{NH}_{4}{ }^{+}$excretion in urine+ hyperkalemia + decreased capacity to lower urine $\mathrm{pH} \rightarrow$ type 1 RTA $\rightarrow$ look for obstructive uropathy.

- Normal plasma $\mathrm{AG}+$ low $\mathrm{NH}_{4}{ }^{+}$excretion in urine+ normal/low plasma potassium $\rightarrow$ confirm type 1 RTA by demonstrating inability to maximally acidify urine in response to spontaneous metabolic acidosis, to acidosis induced by $\mathrm{NH}_{4} \mathrm{Cl}$ or to the furosemide+ fludrocortisone test. Once type 1 RTA is confirmed $\rightarrow$ calculate $\mathrm{FE}$ of $\mathrm{HCO}_{3}{ }^{-}$in the presence of normal bicarbonatemia to assess associated proximal wasting of $\mathrm{HCO}_{3}{ }^{-}$(type $3 \mathrm{RTA}$ ) and confirm that U-B $\mathrm{pCO}_{2}$ in alkaline urine is low to demonstrate the primary origin of the acidification defect. If primary type 1 distal RTA is diagnosed, look for nephrocalcinosis and hypocitraturia and study hearing at diagnosis and in the follow-up.

The above schematic diagnostic approach must be preceded and completed by a detailed anamnesis and family tree, as well as a physical examination particularly focused on the assessment of bone growth and distinctive phenotypic features. Nowadays, the final diagnosis of any type of primary RTA should also lead to the search for mutations in the involved genes [36].

The distinctive biochemical characteristics of each type of primary RTA useful for differential diagnosis are schematically shown in Table 3.

\section{Incomplete distal RTA}

The term incomplete distal RTA refers to an entity of questionable clinical meaning defined by normal acidbase equilibrium in blood, inability to maximally acidify the urine, and normal preservation of $\mathrm{NH}_{4}^{+}$excretion. This disorder has been reported in asymptomatic children with hypocitraturia [37], in children with posterior urethral valves [38], in individuals with osteoporosis [39], and associated with urolithiasis and nephrocalcinosis. Recently, a congenital primary form has also been found in a kindred harboring a heterozygous truncation mutation in the $A T P 6 V 1 B 1$ gene and having hypocitraturia, hypercalciuria, inappropriate urinary acidification after acute $\mathrm{NH}_{4} \mathrm{Cl}$ load, and impaired U-P $\mathrm{pCO}_{2}$ gradient in alkaline urine [40]. 


\section{Key Points}

- RTA is characterized by normal anion gap hyperchloremic metabolic acidosis.

- The four primary types of RTA can be distinguished on the basis of their clinical manifestations, the presenting biochemical profile and, if needed, the response to functional tests. Genetic studies should be performed to identify the involved pathogenic gene but are not strictly necessary for the diagnosis of RTA.

- A correct assessment of urinary acidification capability requires the simultaneous measurement of $\mathrm{pH}$ and ammonium in the same urine sample.

Conflict of interest The authors declare no conflicts of interest.

\section{Questions (answers are provided following the reference list)}

1. All types of RTA are characterized by:
a. Hypokalemic metabolic alkalosis
b. Hyperchloremic metabolic acidosis
c. Hypercalciuria
d. Hyperkalemic metabolic acidosis

2. Nephrocalcinosis is a characteristic radiological finding of:
a. Type 1 RTA
b. Type 2 RTA
c. Type 1 and 2 RTA
d. Type 4 RTA

3. Which of the following statements is true?

a. Type 2 RTA results from impaired $\mathrm{HCO}_{3}{ }^{-}$reabsorption in the proximal tubule

b. Type 4 RTA results from defective production of $\mathrm{NH}_{4}^{+}$by the proximal tubule

c. Type 3 RTA is a mixed form of type 2 and type 4 RTA

d. None of the above

4. All of the following are typical features of primary distal type 1 RTA except

a. Recessive autosomal inheritance in the majority of cases

b. Nephrocalcinosis in at least $50 \%$ of patients

c. Negative urinary anion gap in the presence of acidosis

d. Low or negative urinary-to-blood $\mathrm{pCO}_{2}$ gradient in alkaline urine

5. Regarding the normal response of kidneys to metabolic acidosis, one of the following statements is false a. Urinary $\mathrm{pH}$ is acid $(<5-5.5)$ and $\mathrm{NH}_{4}^{+}$concentration is elevated

b. The reduced ability to lower urine $\mathrm{pH}$ may not be caused by intrinsic defects of renal acidification

c. Elimination of $\mathrm{NH}_{4}{ }^{+}$in urine is higher in acute than chronic metabolic acidosis

d. Bicarbonaturia drops to 0

\section{References}

1. Gil-Peña H, Mejía N, Santos F (2014) Renal tubular acidosis. J Pediatr 164:691-698

2. Fry AC, Karet FE (2007) Inherited renal acidoses. Physiology (Bethesda) 22:202-211

3. Rodríguez-Soriano J (2002) Renal tubular acidosis: the clinical entity. J Am Soc Nephrol 13:2160-2170

4. Wrong O, Bruce LJ, Unwin RJ, Toye AM, Tanner MJ (2002) Band 3 mutations, distal renal tubular acidosis, and Southeast Asian ovalocytosis. Kidney Int 62:10-19

5. Khositseth S, Bruce LJ, Walsh SB, Bawazir WM, Ogle GD, Unwin RJ, Thong MK, Sinha R, Choo KE, Chartapisak W, Kingwatanakul P, Sumboonnanonda A, Vasuvattakul S, Yenchitsomanus P, Wrong O (2012) Tropical distal renal tubular acidosis: clinical and epidemiological studies in 78 patients. QJM 105:861-877

6. Igarashi T, Inatomi J, Sekine T, Cha SH, Kanai Y, Kunimi M, Tsukamoto K, Satoh H, Shimadzu M, Tozawa F, Mori T, Shiobara M, Seki G, Endou H (1999) Mutations in SLC4A4 cause permanent isolated proximal renal tubular acidosis with ocular abnormalities. Nat Genet 23:264-266

7. Gil H, Santos F, García E, Alvarez MV, Ordóñez FA, Málaga S, Coto E (2007) Distal RTA with nerve deafness: clinical spectrum and mutational analysis in five children. Pediatr Nephrol 22:825828

8. Suzuki M, Van Paesschen W, Stalmans I, Horita S, Yamada H, Bergmans BA, Legius E, Riant F, De Jonghe P, Li Y, Sekine T, Igarashi T, Fujimoto I, Mikoshiba K, Shimadzu M, Shiohara M, Braverman N, Al-Gazali L, Fujita T, Seki G (2010) Defective membrane expression of the $\mathrm{Na}(+)-\mathrm{HCO}(3)(-)$ cotransporter $\mathrm{NBCe} 1$ is associated with familial migraine. Proc Natl Acad Sci U S A 107: $15963-15968$

9. Lemann J Jr, Adams ND, Wilz DR, Brenes LG (2000) Acid and mineral balances and bone in familial proximal renal tubular acidosis. Kidney Int 58:1267-1277

10. Katzir Z, Dinour D, Reznik-Wolf H, Nissenkorn A, Holtzman E (2008) Familial pure proximal renal tubular acidosis-a clinical and genetic study. Nephrol Dial Transplant 23:1211-1215

11. Boyden LM, Choi M, Choate KA, Nelson-Williams CJ, Farhi A, Toka HR, Tikhonova IR, Bjornson R, Mane SM, Colussi G, Lebel M, Gordon RD, Semmekrot BA, Poujol A, Välimäki MJ, De Ferrari ME, Sanjad SA, Gutkin M, Karet FE, Tucci JR, Stockigt JR, Keppler-Noreuil KM, Porter CC, Anand SK, Whiteford ML, Davis ID, Dewar SB, Bettinelli A, Fadrowski JJ, Belsha CW, Hunley TE, Nelson RD, Trachtman H, Cole TR, Pinsk M, Bockenhauer D, Shenoy M, Vaidyanathan P, Foreman JW, Rasoulpour M, Thameem F, Al-Shahrouri HZ, Radhakrishnan J, Gharavi AG, Goilav B, Lifton RP (2012) Mutations in kelch-like 3 and cullin 3 cause hypertension and electrolyte abnormalities. Nature 482:98-102

12. Louis-Dit-Picard H, Barc J, Trujillano D, Miserey-Lenkei S, Bouatia-Naji N, Pylypenko O, Beaurain G, Bonnefond A, Sand O, Simian C, Vidal-Petiot E, Soukaseum C, Mandet C, Broux F, 
Chabre O, Delahousse M, Esnault V, Fiquet B, Houillier P, Bagnis CI, Koenig J, Konrad M, Landais P, Mourani C, Niaudet P, Probst V, Thauvin C, Unwin RJ, Soroka SD, Ehret G, Ossowski S, Caulfield M, International Consortium for Blood Pressure (ICBP), Bruneval P, Estivill X, Froguel P, Hadchouel J, Schott JJ, Jeunemaitre X (2012) KLHL3 mutations cause familial hyperkalemic hypertension by impairing ion transport in the distal nephron. Nat Genet 44(456-60):S1-S3

13. Kraut JA, Madias NE (2007) Serum anion gap: its uses and limitations in clinical medicine. Clin J Am Soc Nephrol 2:162-174

14. Carlisle EJ, Donnelly SM, Halperin ML (1991) Renal tubular acidosis (RTA): recognize the ammonium defect and pHorget the urine pH. Pediatr Nephrol 5:242-248

15. Wrong O (1991) Distal renal tubular acidosis: the value of urinary $\mathrm{pH}, \mathrm{PCO}_{2}$ and $\mathrm{NH}_{4}{ }^{+}$measurements. Pediatr Nephrol 5:249-255

16. Batlle DC, Hizon M, Cohen E, Gutterman C, Gupta R (1988) The use of the urinary anion gap in the diagnosis of hyperchloremic metabolic acidosis. N Engl J Med 318:594-599

17. Sulyok E, Guignard JP (1990) Relationship of urinary anion gap to urinary ammonium excretion in the neonate. Biol Neonate 57:98106

18. Kim GH, Han JS, Kim YS, Joo KW, Kim S, Lee JS (1996) Evaluation of urine acidification by urine anion gap and urine osmolal gap in chronic metabolic acidosis. Am J Kidney Dis 27:42-47

19. Kraut JA, Madias NE (2012) Differential diagnosis of nongap metabolic acidosis: value of a systematic approach. Clin J Am Soc Nephrol 7:671-679

20. Edelmann CM Jr, Boichis H, Rodriguez-Soriano J, Stark H (1967) The renal response of children to acute ammonium chloride acidosis. Pediatr Res 1:452-460

21. Walsh SB, Shirley DG, Wrong OM, Unwin RJ (2007) Urinary acidification assessed by simultaneous furosemide and fludrocortisone treatment: an alternative to ammonium chloride. Kidney Int 71:1310-1316

22. Edelmann CM Jr, Rodriguez-Soriano J, Boichis H, Gruskin AB, Acosta MI (1967) Renal bicarbonate reabsorption and hydrogen ion excretion in normal infants. J Clin Invest 46:1309-1317

23. Brenes LG, Sanchez MI (1993) Impaired urinary ammonium excretion in patients with isolated proximal renal tubular acidosis. $\mathrm{J}$ Am Soc Nephrol 4:1073-1078

24. McSherry E, Sebastian A, Morris RC Jr (1972) Renal tubular acidosis in infants: the several kinds, including bicarbonate-wasting classic renal tubular acidosis. J Clin Invest 51:499-514

25. Rodriguez-Soriano J, Vallo A, Garcia-Fuentes M (1975) Distal renal tubular acidosis in infancy: a bicarbonate wasting state. J Pediatr 86:524-532

26. Ohlsson A, Cumming WA, Paul A, Sly WS (1986) Carbonic anhydrase II deficiency syndrome: recessive osteopetrosis with renal tubular acidosis and cerebral calcification. Pediatrics 77:371-381

27. Ismail EAR, Saad SA, Sabry MA (1997) Nephrocalcinosis and urolithiasis in carbonic anhydrase II deficiency syndrome. Eur J Pediatr 156:957-962
28. Nagai R, Kooh SW, Balfe JW, Fenton T, Halperin ML (1997) Renal tubular acidosis and osteopetrosis with carbonic anhydrase II deficiency: pathogenesis of impaired acidification. Pediatr Nephrol 11: 633-636

29. Sebastian A, Morris RC Jr (1977) Renal tubular acidosis. Clin Nephrol 7:216-230

30. Santos F, Orejas G, Foreman JW, Chan JCM (1991) Diagnostic work-up of renal disorders. Curr Probl Pediatr 21:48-74

31. Dinour D, Chang MH, Satoh J, Smith BL, Angle N, Knecht A, Serban I, Holtzman EJ, Romero MF (2004) A novel missense mutation in the sodium bicarbonate cotransporter (NBCe1/SLC4A4) causes proximal tubular acidosis and glaucoma through ion transport defects. J Biol Chem 279:52238-52246

32. Alon U, Hellerstein S, Warady BA (1991) Oral acetazolamide in the assessment of (urine-blood) $\mathrm{PCO}_{2}$. Pediatr Nephrol 5:307-311

33. Sly WS, Whyte MP, Krupin T, Sundaram V (1985) Positive renal response to intravenous acetazolamide in patients with carbonic anhydrase II deficiency. Pediatr Res 19:1033-1036

34. Batlle DC (1986) Segmental characterization of defects in collecting tubule acidification. Kidney Int 30:546-554

35. Rodríguez-Soriano J, Vallo A (1988) Renal tubular hyperkalaemia in childhood. Pediatr Nephrol 2:498-509

36. Mejía N, Santos F, Claverie-Martín F, García-Nieto V, Ariceta G, Castaño L, RenalTube group (2013) RenalTube: a network tool for clinical and genetic diagnosis of primary tubulopathies. Eur J Pediatr 172:775-780

37. Norman ME, Feldman NI, Cohn RM, Roth KS, McCurdy DK (1978) Urinary citrate excretion in the diagnosis of distal renal tubular acidosis. J Pediatr 92:394-400

38. Zhang J, Fuster DG, Cameron MA, Quiñones H, Griffith C, Xie XS, Moe OW (2014) Incomplete distal renal tubular acidosis from a heterozygous mutation of the V-ATPase B1 subunit. Am J Physiol Ren Physiol 307:F1063-F1071

39. Sharma AP, Singh RN, Yang C, Sharma RK, Kapoor R, Filler G (2009) Bicarbonate therapy improves growth in children with incomplete distal renal tubular acidosis. Pediatr Nephrol 24:15091516

40. Weger W, Kotanko P, Weger M, Deutschmann H, Skrabal F (2000) Prevalence and characterization of renal tubular acidosis in patients with osteopenia and osteoporosis and in non-porotic controls. Nephrol Dial Transplant 15:975-980

\section{Answers}

1. B

2. A

3. A

4. C

5. C 